\title{
GROUNDED THEORY METHODOLOGY FOR UNDERSTANDING HOW EQUINE ASSISTED LEARNING CONTRIBUTES TO ADULT LEARNING
}

\author{
Ilona Gehtmane-Hofmane \\ University of Latvia, Latvia
}

\begin{abstract}
The aim of this article is to provide a theoretical review of Grounded Theory methodologies and their application in research, to understand how adults learn through guided human and horse interaction during an Equine Assisted Learning session. There are many debates about similarities and differences between Glaserian Grounded Theory (GGT), Strauss and Corbin Grounded Theory (SGT) and Constructivist Grounded Theory (CGT). All three approaches have been analyzed with the aim of understanding mutual similarities and differences between them, as well as understanding original ideas for conceptualizing these approaches and to select a Grounded Theory approach that best matches the research question - how adults learn when the learning takes place through guided human and horse interaction during an Equine Assisted Learning session.
\end{abstract}

Key words: Adult learning, Equine Assisted Learning, Grounded Theory.

\section{Introduction}

"The central question of how adults learn has occupied the attention of researchers and educaters since the founding of adult education as a professional field of practice in the 1920s" (Merriam, 2001, p. 1). As well as is one of the central questions in an emerging discipline named Learning Sciences (Fischer et al., 2018).

Adult learning is a extremly wide area of research and theory building. The knowledge and uderstanding about how adults learn is in the spotlight of practice development for adult education. There are many learning theories, but there is no one theory of adult learning that explains all that is known about adult learners, the process of learning, and the various contexts where learning takes place. Because learning is a complex process that can never be reduced to one simple explanation.

The notion Equine Assisted Learning (EAL) in academic literature is new and it appeared only at the beginning of the $20^{\text {th }}$ century. EAL could be defined as an innovative learning practice where learning takes place 
through guided human and horse interactions that offers an individual and unique learning experience. EAL practice has taken place in a variety of settings. Currently, there are several hundred programs across the world that utilize these programmes for different learning needs. It seems there are no bounds to the creativity involved when putting people and horses together for whatever reason. The positive outcomes that can be obtained from learning activities with horses are primarily illustrated through the marketing literature, and feedback from participants or practitioners. EAL practice is based on empirical work and is not theoretically founded in research data. There is a need to initiate scientific dialogue about the importance of learning in an EAL practice. The existing approaches and types of EAL points to the fact that this form of learning has a high applicability potential. Learning is a multidimensional phenomenon, the more we know about how adults learn in an EAL practice, the better we are able to structure EAL activities that resonate with those adult learners with whom we work. Nevertheless all EAL programs have one common feature human learning. There is not one theory founded in research data that explains - how adults learn through guided human and horse interaction during EAL session and how this learning results (Gehtmane-Hofmane, Nìmante, 2015; Gehtmane-Hofmane, 2018; Gehtmane-Hofmane, 2019).

Aim of the Study - to do empirical research and investigate and develop an analytical framework for understanding how adults learn when the learning takes place through guided human and horse interaction, and describes the different perspectives on how this learning occurs and results. The research question "how adults learn" to be viewed in the framework of Equine Assisted Learning practice as a learning space, where primary learning takes place.

One of the study tasks and aims of this article - is to understand Grounded Theory methodologies and their application in research for understanding how adults learn when the learning takes place through guided human and horse interaction during EAL session. There are many debates about similarities and differences between Grounded Theory (GT) approaches. Three approaches have been analyzed with the aim of understanding mutual similarities and differences between them, as well as understanding original ideas for conceptualizing these approaches and to select a GT approach that best matches the aim of research.

\section{Background}

Grounded Theory (GT) is a qualitative research methodology, that focuses on generating theories from the data. GT offers analytical techniques for qualitative content analysis. There are three prevailing approaches: 
Glaserian GT - originally developed by Glaser and Strauss (Glaser, Strauss 1967; Glaser, 2013), Straussian GT - originally developed by Straus and the latter co-developed with Corbin (Strauss, 1987; Straus, Corbin, 1990, Corbin, Strauss, 2015), and Constructivist GT which was developed by Kathy Charmaz (Charmaz, 2000; Charmaz, 2006; Charmaz, 2014; Charmaz, 2018). To select a Grounded Theory approach that matches the research question and the study's purpose, as well as the author's own perspectives and needs, an analysis has been carried out on all three Grounded Theory approaches. This article involves the analysis of primary data and academic literature written by leaders in the field of GT. Despite their divergence all three approaches claim the same origin and to embrance similar methodological techniques, but there are differences.

Differences and similarities relating to guiding theories and assumptions:

Glaserian GT based on critical realism, post - positivism and positivism, fostered orthodox view, mirrored a modernist epistemology and objectivist assumptions. Straussian GT based on positivist assumptions, is compatible with symbolic interactionism, pragmatist philosophical tradition, constructivist currents, assumed social constructionism approach in a more limited form and adopts a realist position. Constructivist GT based on constructivism, relativist epistemology, social constructionism, adopts a realist position, takes a middle ground between postmodernism and positivism, symbolic interactionist theoretical perspective (Charmaz, 2000; Charmaz, 2006; Charmaz, 2014; Charmaz, 2018; Corbin, Strauss, 2015; Glaser, Strauss, 1967; Glaser,. 2013; Strauss, 1987; Strauss, Corbin, 1990). Because of the differences, GT potentially offers methodologies for a variety of research and for researchers. Researchers with different worldviews, and different research questions, can chose a GT approach that matches their own perspectives and needs.

Differences and similarities regarding data collection and analysis: In all three approaches data collection and analysis proceeds simultaneously. The process of analysis is cyclical as is the process of data collection, coding, categorization and theoretical sampling. All three approaches offer constant comparative methods which involves making comparisions during each stage of the analysis to establish analytic distinctions. In a Constructivist GT approach data analysis begins to develop theories (explanations) that suggest further cases to sample and researchers can use GT strategies with a variety of data collection methods (Charmaz, 2000; Charmaz, 2006; Charmaz, 2014; Charmaz, 2018; Corbin, Strauss, 2015; Glaser, Strauss, 1967; Glaser, B. 2013; Strauss, 1987; Strauss, Corbin, 1990). Across all GT approaches the data collection and analysis is systematic, and researchers may find it helpful particularly if they are new in using GT. 
Differences and similarities regarding the character of data: In Glaserian GT and Straussian GT date is self-evident and speaks for itself. In a Constructivist GT data is a product of the research process, the research and the researcher co-construct the data. Data is a narrative construction, and reconstructions of experience to build data in an interactive and cointerpreted way (Charmaz, 2000; Charmaz, 2006; Charmaz, 2014; Charmaz, 2018; Corbin, Strauss, 2015; Glaser, Strauss, 1967; Glaser, B. 2013; Strauss, 1987; Strauss, Corbin, 1990).

In Glaserian GT and Straussian GT external reality is independent from the researcher (Corbin, Strauss, 2015; Glaser, Strauss, 1967; Glaser, B. 2013; Strauss, 1987; Strauss, Corbin, 1990). In Constructivist GT external reality depends on interaction between the researcher and research participant. Constructivist GT represents research participants as the constructor of reality that serves as the data. Participants reflect experience and behave like "free agents" with their own needs and interests, as a unique and autonomous individual (Charmaz, 2000; Charmaz, 2006; Charmaz, 2014; Charmaz, 2018; Corbin, Strauss, 2015; Glaser, Strauss, 1967; Glaser, B. 2013; Strauss, 1987; Strauss, Corbin, 1990)

Differences and similarities regarding role of researcher: In Glaserian GT the researcher stands outside the research process. The researcher is a passive, neutral observer who collects the facts but did not participate in creating the data. The researcher is "tabula rasa" (blank slate), a distanced expert generating a theory by careful application of all GT procedures minimizing human bias. The researcher should not impose their own views on the data and does not compose the story and their own experience on the data. Conceptualization into categories should also be abstract of researcher interpretation. The researchers experience may just be more data. He raises participants' perspectives to the abstract level of conceptualization and data and theoretical sensitivity is central (Glaser, Strauss, 1967; Glaser, B. 2013). Straussian GT strategies encourage the researcher to be do an active analysis of the data. According Strauss and Corbin (1990) the goal is for the researcher to increasingly possess "the attribute of having insight, the ability to give meaning to the data, the capacity to understand, and the capability to separate the pertinent from that which it isn't" (Strauss, Corbin, 1990, p.41). In Constructivist GT the researcher is a part of the studied process and research situations. The task for the researcher is to learn the methods by which participants construct their realities and to make further interpretations about this reality through critically examining their construction of the research process as they seek to analyze how their research participants construct their experience. The researcher makes an interactive impact on the data and co-composes the story. The story reflects the viewer as well as the viewed. The researcher develops and proposes 
a new understanding and a novel theoretical interpretation of the studied field that reflects the experiences and interactions of the participants and the researcher. According to Charmaz (2006), the researcher constructs data through observations, interactions and materials about the topic or setting, empirical events and experiences and pursues hunches and potential analytic ideas about the data. The central focus is on action and experience from the experiencing subject perspectives, on mutual creation of knowledge by the researcher and the research, and on the interpretive understanding of the subjects' meanings (Charmaz, 2000; Charmaz, 2006; Charmaz, 2014; Charmaz, 2018).

In all three approaches, the analytic process employed, prompts theory discovery and development rather than verification of pre-existing theories. They offer the same analytic strategies but differ a little regarding coding strategy and types of codes. For example; Constructivist GT has both initial codes and in-vivo codes. In-vivo codes are used for participant's special terms, it helps to preserve the participants meaning of their views. Invivo codes serve as both symbolic markers of the participant's speech and meaning. Like any other code, these codes need to be integrated into the theory and they need to be subjected to comparative and analytic treatment. In all three approaches categories are building from these codes, but in Constructivist GT there is a much wider range of analytical categories. 15 analytical categories were identified: narrow categories, pre-conceived/ pre-existing categories, subcategories, theoretical categories, core categories/general categories, major and minor categories, unintegrated categories, abstract categories, disciplinary categories, overlapping categories, potential categories, subsequent categories, low-level categories, conceptual categories and tentative categories (Charmaz, 2000; Charmaz, 2006; Charmaz, 2014; Charmaz, 2018; Corbin, Strauss, 2015; Glaser, Strauss, 1967; Glaser, B. 2013; Strauss, 1987; Strauss, Corbin, 1990).

Differencies and similarities regarding provided guidelines: Glaserian GT provides directive instructions and a strong justification for inductive qualitative inquiry. Straussian GT provides semi-flexible instructions and offers guidelines for prescribed procedures in concrete ways. Constructivist GT provides flexible guidelines that allow the researcher to adopt the method for the study and the specificity of the phenomenon being studied. It also offers general principles rather that directive instructions and rules. No set of rules dictate when and what the researcher needs to do (Charmaz, 2000; Charmaz, 2006; Charmaz, 2014; Charmaz, 2018; Corbin, Strauss, 2015; Glaser, Strauss, 1967; Glaser, B. 2013; Strauss, 1987; Strauss, Corbin, 1990).

Glaserian GT delays a lliterature review and the researcher should begin research without the guidance of pre-conceived questions and theory. 
Straussian GT also advocates delaying the literature review to avoid seeing the world through the lens of extant theories, however it does allow the researcher to do research with the guidance of pre-conceived open questions. Constructivist GT disavows the idea that the researcher should begin their studies without prior knowledge and theories about their topic. The researcher must have prior knowledge and theoretical pre-conceptions regarding their research field (Charmaz, 2000; Charmaz, 2006; Charmaz, 2014; Charmaz, 2018; Corbin, Strauss, 2015; Glaser, Strauss, 1967; Glaser, B. 2013; Strauss, 1987; Strauss, Corbin, 1990).

Glaserian GT and Constructivist GT deals best with the research questions "how" and "what", however Straussian GT deals with research questions "how", "why" and "what" (Charmaz, 2000; Charmaz, 2006; Charmaz, 2014; Charmaz, 2018; Corbin, Strauss, 2015; Glaser, Strauss, 1967; Glaser, B. 2013; Strauss, 1987; Strauss, Corbin, 1990)

Differences and similarities regarding goals and some tenets. Glaserian GT generates formal or middle-range theories from the data and seeks explanations and predictions at a general level. This approach produces conceptually generated theory and examined hypotheses by measuring variables. Glaserian $G T$ develops theories from research grounded in data rather than deducting testable hypotheses from existing theories. Led for valid instruments, procedures, replicable research designs, and verifiable quantitative generalizable knowledge - reducing qualities of human experience to quantifiable variables and to deal with facts rather than with what someone has said about them. Straussian GT generates formal, middlerange or substantive theories from the data. In generating substantive theory, it seeks theoretical interpretations or explanations of a delimited problem or theory applicable to a specific field. Constructivist GT generates a theory from empirical data through explanation and understanding at a general level and seeks to develop an interpretive understanding of the studied phenomenon. Constructivist GT focuses on the research process, which is characterized by partnership and collaboration and seeks to understand the subjective experience and described processes (Charmaz, 2000; Charmaz, 2006; Charmaz, 2014; Charmaz, 2018; Corbin, Strauss, 2015; Glaser, Strauss, 1967; Glaser, B. 2013; Strauss, 1987; Strauss, Corbin, 1990).

\section{Conclusions}

The Equine Assisted Learning process is characterized by partnership and collaboration and the learning process is based on action and experience from the experiencing subject's perspectives. Unlike Glaserian GT and Straussian GT, Constructivist GT offers a collaborative approach to the research process and knowledge building. It focuses on the research 
process, which is characterized by partnership and collaboration and helps to understand the subjective experience of the research participants. It also describes the processes required to develop an interpretive understanding of the studied phenomenon from the perspective of a subjective experience. The data analysis and data collection are also subjective. Constructivist GT focuses on a mutual creation of knowledge by the researcher and research participant.

The Constructivist GT approach offers basic GT strategies with adopted Glaserian GT and Straussian GT methodological approaches and provides flexible guidelines that allow the researcher to adopt the method for the study and the specificity of the phenomenon being studied. Unlike Glaserian GT and Straussian GT, in Constructivist GT the data is a product of the research process, the researcher and research participants co-construct the data. Data is a co-construction and reconstruction of experience and depends from interaction between the researcher and research participant in the research process. The Equine Assisted Learning (EAL) process creates a learning experience that is a product of EAL and depends on the interaction between the horse, facilitator and the learner - (research participant). In both - EAL and Constructivist GT interactions, the experience, reflection and reflexivity are central. Unlike Glaserian GT and Straussian $G T$, the Constructivist GT approach emphasizes relativity not generality and reflexivity not objectivity and disagrees that the researcher should begin their studies without prior knowledge and theories about their topic. It means that the researcher must have prior knowledge and theoretical pre-conceptions about Equine Assisted Learning as the research field and adult learning as research topics. Constructivist GT deals best with research questions "how" and "what", for example - "how" adults learn, "how" this learning occurs and the results. Unlike Glaserian GT and Straussian GT, in Constructivist GT the researcher is part of the studied process and research situations. He or she has two roles - objective observer and active research participant with influence on the data and analytic processes. The researchers make an impact on the data and co-compose the story together with the research participant. It means that the story reflects the researcher as well as the research participant (learner) experience of learning within the Equine Assisted Learning sessions. Unlike Glaserian GT and Straussian GT, Constructivist GT represents research participants as the constructor of their own and unique reality, their needs and interests serve as the data. Either of the learning outcomes from Equine Assisted Learning sessions depends on the learner's experience, values, needs, interests and ability to learn.

Investigation of the Equine Assisted Learning process to understand how adults learn when the learning takes place through guiding human and 
horse interaction and understand the different perspectives, for example, how research participants create the meaning of a learning situation, how this learning occurs and what results have strong constructivism leanings. Unlike Glaserian GT and Straussian GT, Constructivist GT offers basic GT steps and provides methodological guidance, that is flexible enough with enough explanation and suggestions, which could be used as a work guide in an organization of this study. Constructivist GT offers guidelines for anyone who has a basic knowledge of research methods. There is one more important aspect when choosing a Constructivist GT approach in this study, this is the lack of the author's experience in using this method.

\section{References}

Corbin, J. M., Strauss, A. L. (2015). Basics of qualitative research: Techniques and procedures for developing grounded theory ( $4^{\text {th }}$ ed.). Retrieved from: https://books.google. lv $/$ books? id $=$ hZ6kBQAAQBAJ\&printsec $=$ frontcover\&source $=$ gbs_ge_summary_r\& $\mathrm{cad}=0 \# \mathrm{v}=$ onepage $\& \mathrm{q} \& \mathrm{f}=$ false.

Charmaz, K. (2000). Constructivist and objectivist grounded theory. In N. Denzin and Y. Lincoln (Eds.). Handbook of qualitative research, $2^{\text {nd }}$ ed., pp. 509-535. SAGE Publications.

Charmaz, K. (2006). Constructing Grounded Theory: A Practical Guide Through Qualitative Analysis. Retrieved from: https://books.google.lv/books?id=w2sDdv-S7Pg $\mathrm{C} \& \mathrm{pg}=$ PA130\&lpg $=$ PA130\&dq $=$ charmaz $+2000 \&$ source $=$ bl\&ots $=$ p0qk4UFJax \&sig $=$ ACfU3U1qDjUJ64h6wl_hE5LlRZKuE_Xdxw\&hl =lv\&sa =X\&ved $=$ 2ahUKEwiWw8_r26PjA $\mathrm{hXi0qYKHWBYDA0Q6AEwCXoECAgQAQ \# v}=$ onepage $\& \mathrm{q} \& \mathrm{f}=$ false.

Charmaz, K. (2014). Constructing grounded theory. ( $2^{\text {nd }}$ ed.). SAGE Publications.

Charmaz, K. (2018). Thinking About Data With Grounded Theory. Retrieved from: https://www.researchgate.net/publication/328945741_Thinking_About_Data_With_ Grounded_Theory.

Fischer, F., Hmelo-Silver, C. E., Goldman, S. R., Reimann P. (Eds.) (2018). International Handbook of the Learning Sciences. Retrieved from: https://books.google.lv/books?id $=$ JUxWDwAAQBAJ\&printsec $=$ frontcover\&source $=$ gbs_ge_summary_r\&cad $=0 \# \mathrm{v}=$ one page \&q\&f $=$ false.

Gehtmane-Hofmane I., Nīmante D. (2015). Equine Assisted Interventions: History, development, types and models of practice. Challenges and solutions for education in the $21^{\text {st }}$ Century. "2015 ATEE Spring Conference - Teacher of the $21^{\text {st }}$ Century: Quality Education for Quality Teaching". Retrieved: https://books.google.lv/books?id=gO22D QAAQBAJ\&pg $=$ PA292\&lpg $=$ PA292\&dq $=$ Equine + Assisted + Interventions: + History, + development, + types + and + models + of + practice\&source $=$ bl\&ots $=1 \mathrm{MA} 9 \mathrm{Bj} 32 \mathrm{yP} \& \mathrm{~s}$ ig = ACfU3U0AW0kOPOpeyBQpjPJKnk437MA-_Q\&hl = lv\&sa = X\&ved = 2ahUKEwiBjcz1 5qPjAhVnsIsKHUglArsQ6AEwAHoECAoQAQ\#v = onepage\&q = Equine\%20Assisted $\% 20$ Interventions $\% 3 \mathrm{~A} \% 20 \mathrm{History} \% 2 \mathrm{C} \% 20$ development $\% 2 \mathrm{C} \% 20$ types $\% 20$ and $\% 20$ models $\% 20$ of $\% 20$ practice $\& \mathrm{f}=$ false.

Gehtmane-Hofmane I. (2018). Equine assisted learning: Symbolic value of horse as underlying pattern in human thinking. "SOCIETY, INTEGRATION, EDUCATION". DOI: http://dx.doi.org/10.17770/sie2018vol1.3379. ISSN 1691-5887. 
Gehtmane-Hofmane, I. (2019). The unique characteristics of horses for human learning purposes in Equine Assisted Learning practice. INTERNATIONAL JOURNAL OF SMART EDUCATION AND URBAN SOCIETY. Issue 10 (3) pp. 85-91, ISSN25969852.

Glaser, B. G., Strauss, A. L. (1967). The discovery of grounded theory: Strategies for qualitative research. Retrieved from: http://www.sxf.uevora.pt/wp-content/ uploads/2013/03/Glaser_1967.pdf.

Glaser, B. (2013). No Preconceptions: The Grounded Theory Dictum. Sociology Press.

Merriam, S. B. (2001). Andragogy and Self-Directed Learning: Pillars of Adult Learning Theory. New Directions for Adult \& Continuing Education. Spring 2001, Vol. 2001, Issue 89, pp. 3-11. DOI: 10.1002/ace.3. Database: Academic Search Complete.

Strauss, A. L. (1987). Qualitative analysis for social scientists. Retrieved from: https:// books.google.lv/books? id $=$ y16ww5ZsJ0AC\&printsec $=$ frontcover\&source $=$ gbs_ge_sum mary_r\&cad $=0 \# \mathrm{v}=$ onepage \&q\&f$=$ false.

Strauss, A. L., Corbin, J. M. (1990). Basics of qualitative research: Grounded theory procedures and techniques. Sage Publications. 